\title{
TECENDO REFLEXÕES SOBRE O CURRÍCULO E A SINGULARIDADE DO FAZER PEDAGÓGICO
}

\author{
Nayara Tatianna Santos da Costa $^{1}$
}

\section{Resumo}

O artigo aborda reflexões sobre currículo nos limiares das reformas políticas dos anos de 1990 e como tais reformas influenciaram nas discussões sobre o Currículo no Brasil. Sob um enfoque qualitativo e bibliográfico, o estudo em questão centra seu olhar sob a problemática do conhecimento e o Currículo na organização do trabalho na escola, discutindo sobre as implicações da sociedade informacional e tecnológica e seus reflexos nas dinâmicas escolares. Em seguida utilizamos das metáforas da árvore e do rizoma para questionar a fragmentação do currículo escolar e debater sobre as possibilidades de construção de uma forma interdisciplinar de produção do conhecimento e reformulação do fazer pedagógico nas escolas. Apoiadas em autores como Alarcão, Geraldi, Gallo, entre outros, finalizamos nossa discussão indagando sobre a pretensa autonomia docente proferida pelas políticas curriculares para o fazer pedagógico, mas entendendo estas, como engessadas pela forma "sutil" de como se constitui o PCN, ou melhor seria chamar de currículo mínimo nacional assim como nos aponta Geraldi? Pretendemos desse modo, contribuir para a reflexão sobre a necessidade de se construir uma Educação de qualidade social, que favoreça uma formação ampla igualitária e crítica para os sujeitos, no sentido de que estes possam se constituir enquanto cidadãos de fato.

Palavras-Chave: Currículo, Educação pública e Qualidade social.

\begin{abstract}
The article discusses the curriculum reflections on the thresholds of the politic reforms of the 1990s and how these reforms influenced the discussions on the curriculum in Brazil. From a qualitative perspective and literature, the present study focuses his gaze upon the problematic of knowledge and curriculum in the organization of work at school, discussing the implications of the information society and technology and their effects on school dynamics. Then we use the metaphor of the tree and the rhizome to question the fragmentation of the curriculum and discuss the possibilities of building an interdisciplinary knowledge production and reformulation of pedagogical schools. Supported by authors such as Alarcão, Geraldi, Gallo, among others, we concluded our discussion by questioning the alleged teaching autonomy given by the curricular politics for pedagogical practice, but understanding these, as casts by how "subtle" of what constitutes a PCN or best would be to call the national minimum curriculum as well as in points Geraldi? We intend thereby to contribute to the reflection on the need to build a social quality education that fosters extensive training egalitarian and critical to the subjects, in the sense that they can be constituted as citizens of fact.
\end{abstract}

Keywords: Curriculum, Public Education and Social Quality.

\footnotetext{
${ }^{1}$ Professora da Universidade Federal de Campina Grande-PB, Mestre em Educação-UFPB. Trabalho em coautoria com Kiara Tatianny Santos da Costa, Doutoranda em Educação-UFPE, Mestre em Educação UFPB
}

ISSN 1983-1579 


\section{A REFORMA DOS ANOS 1990 E SUAS IMPLICAÇõES PARA A EDUCAÇÃO}

Os anos 1990 marcam um cenário de mudanças na sociedade brasileira, as quais repercutem também em transformações no panorama das políticas educacionais. Nesse contexto, portanto, sob a argumentação neoliberal de que o Estado está em crise, são previstas uma série de estratégias de superação dessa tensão, as quais se fundam sobretudo, em uma minimização do papel do Estado sobre as políticas sociais, passando este de principal promotor dessas políticas, para atuar como o seu regulador. Essa nova configuração, imprime diversos contornos para a condução das políticas públicas de educação, e simultaneamente para o fazer pedagógico nos cotidianos escolares.

Para que possamos refletir acerca dessas mudanças, é necessário nos situarmos um pouco na conjuntura dessa reforma ou da reconfiguração do papel do Estado. Assim, segundo Peroni e Adrião (2005) entre as principais causas apontadas pelo discurso neoliberal para o cenário de crise do Estado seria o excessivo gasto governamental com as políticas sociais, que teria onerado os cofres públicos, no atendimento às demandas da população. As autoras questionam esse argumento afirmando que a crise seria do capital e não do Estado. E abordam ainda que o neoliberalismo atribui ao mercado a capacidade de superação dessa crise.

Esse ponto é importante, pois é a partir dessa argumentação que no governo de Fernando Henrique Cardoso, em 1995 surge o Documento que materializa a proposta de redefinição do papel do Estado: o Plano Diretor de Reforma do Aparelho do Estado. Esse documento pretendia em linhas gerais, de acordo com Bueno e Kassar (2005), delimitar as funções e o tamanho do Estado, a redefinição do papel regulador, o aumento da governança; que é a capacidade de tornar efetivas as decisões do governo, e o aumento da governabilidade; que se refere ao poder do governo.

Dentro do Plano Diretor era prevista uma divisão do aparelho do Estado em quatro setores, quais sejam: O primeiro, chamado de núcleo estratégico, no qual as leis e políticas seriam definidas, o segundo, das atividades exclusivas do Estado, ou seja apenas ele poderia realizar, o terceiro, dos serviços não exclusivos, em que o Estado atuaria simultaneamente com outras organizações sociais, públicas não estatais e privadas. Nesse setor, estariam então incluídos os serviços de educação. Por último, o quarto setor, onde se localizariam a produção de bens e serviços para o mercado.

Assim, dentre a argumentação neoliberal de existência de uma crise no Estado, 
o mercado figura como sua possibilidade de superação. Nesse sentido, são adotadas diversas estratégias pelo governo federal. Uma delas é a privatização, que se refere à transferência de propriedade para a iniciativa privada. Outra pode ser descrita como publicização; que é a transferência para o setor público não estatal de serviços sociais e científicos. E, por último, a terceirização, que é uma transferência de serviços auxiliares e de apoio ao setor privado.

Vale ressaltar que, a educação, tomada agora no sentido de um serviço não exclusivo, passa também a ser oferecida por instituições não estatais ou privadas, e a estrutura estatal acaba sendo "invadida" por uma lógica inerente ao mercado, sob o viés de uma percepção que desqualifica os serviços oferecidos pelo Estado, considerando-os como ineficientes. 0 discurso da eficiência portanto, é subliminar à justificativa de inserção da ideologia de mercado na educação.

Aliadas a essas ações, estão ainda outras, que, sustentadas pelo discurso da eficiência do mercado, corroboram para transformações profundas nas relações estabelecidas entre os sujeitos, o conhecimento e a educação escolar.

Como afirmam Adrião e Peroni (2009, p. 3):

Para o ex-ministro Bresser Pereira, a interpretação da crise do Estado e a consequente estratégia social liberal, que fundamentam o Plano de Reforma do Estado, tomam emprestadas do paradigma neoliberal a sua crença no mercado e o diagnóstico acerca da crise ser originada no Estado. Porém, ao invés de optar exclusivamente pela diminuição do aparato estatal mediante a privatização de sua estrutura e pela transferência para o mercado da oferta de serviços públicos, indica a necessidade de reformá-lo, por meio da adoção de mecanismos de gestão vigentes no campo empresarial.

Nesse contexto, as autoras contribuem no sentido de compreender as tendências pelas quais o Estado vai sendo redesenhado. Por um lado o Estado sai de cena quanto à execução de determinados serviços, mantendo-se como financiador e avaliador. Por outro, mesmo nos casos em que os serviços se mantêm sob propriedade do Estado, eles são gerenciados por uma lógica ditada pelo mercado. Logo, essa última tendência é o que muitos denominam de quase mercado.

Nessa perspectiva de quase mercado, a educação e o cotidiano do fazer pedagógico vão sendo influenciados significativamente por essa nova realidade, o que corrobora para que a autonomia desse fazer seja comprometida. E que a qualidade defendida 
nesse espaço seja a qualidade apregoada pelo mercado, e que se fundamenta sobretudo nos parâmetros ditados pela lógica do mercado, pela produtividade e pela competitividade.

Logo, o papel desempenhado pelos profissionais docentes, que a rigor, deveriam pensar sua ação de modo consciente, uma vez considerados tal como Isabel Alarcão nos apresenta a partir da visão de professores reflexivos, também é comprometido. Esse comprometimento se expressa já na sua formação, que passa então a ser subordinada aos interesses do capital e que requer profissionais competentes, produtivos. E que muitas vezes se deparam com uma formação calcada apenas na esfera do ensino, na medida em que essas atividades são priorizadas pela iniciativa privada, setor que ocupa um espaço privilegiado na formação desses profissionais, negligenciando a pesquisa e a extensão. Além disso, há também o prejuízo causado pelas políticas de aligeiramento que tem sido marcante também na formação inicial desses profissionais.

É nesse âmbito, portanto, que se situam algumas mudanças ocorridas a partir da década de 1990, e dos novos papéis impressos as realidades social e educacional brasileiras, através da redefinição do papel do Estado, que imprimem contornos de gerenciamento das ações e fazeres, didático-pedagógicos, determinando de certo modo o que deve ser ensinado e que tipo de sujeitos/profissionais queremos formar.

\section{CONSIDERAÇÕES SOBRE CONHECIMENTO E CURRÍCULO NA DINÂMICA DO TRABALHO NA ESCOLA}

O conhecimento e a informação hoje constituem elementos bastante importantes na vivência em sociedade. Vivemos um constante bombardeio de informações que nos são oferecidas através de uma série de mecanismos, como a internet por exemplo. Mas como processar essas informações desconectadas, tornando-as um todo coeso, atribuindo-lhe algum sentido? A escola, nesse âmbito, ocupa, ou deveria ocupar um lugar de destaque, conseguindo estabelecer essas conexões e colaborando para que seus estudantes possam compreender a complexidade do mundo que os rodeia. Mas será que é isso que ela está fazendo?

As metáforas da árvore e do rizoma podem contribuir nessa reflexão. A primeira nos apresenta a totalidade do conhecimento sob a representação de um tronco de uma árvore, cujas ramificações reproduzem as especializações desse saber, e que de maneira ampla, mostram o conhecimento a partir de saberes fragmentados, (os galhos) e hierarquizados (galhos ramificam-se e não se comunicam entre si). Esse modelo de compreensão ajuda-nos a entender o conhecimento no seu aspecto fragmentado, que não 
consegue ser captado no seu conjunto, uma vez que seus saberes não estão interligados e não se comunicam entre si. O que nos faz pensar em como foi e é formatada nossa escola e o currículo, que de forma majoritária ocupa espaço nesses ambientes educativos.

Em contraste, no que tange ao modelo epistemológico do rizoma, este pode representar o conhecimento de uma maneira bem diversa daquela representada pela metáfora arbórea. Caracterizado por uma estrutura de miríade de pequenas raízes emaranhadas, a noção de rizoma representa a relação intrínseca entre as diversas áreas do saber, o que diverge do caráter de fragmentação que decorre do modelo epistemológico da árvore. A partir do rizoma, percebemos a possibilidade de interconexão entre os saberes e a forma como esse relacionamento pode corroborar para a visão de conjunto, que ultrapassa a forma fragmentada de percepção possibilitada pelo modelo anterior. Conforme Gallo (2001, p.30).

A metáfora do rizoma subverte a ordem da metáfora arbórea, tomando como paradigma imagético aquele tipo de caule radiciforme de alguns vegetais, formado por uma miríade de pequenas raízes emaranhadas em meio a pequenos bulbos armazenatícios, colocando em questão a relação intrínseca entre as várias áreas do saber, representadas cada uma delas pelas inúmeras linhas fibrosas de um rizoma, que se entrelaçam e se engalfinham formando um conjunto complexo no qual os elementos remetem necessariamente uns aos outros e mesmo para fora do próprio conjunto.

Ambos os exemplos constituem elementos que favorecem nossa reflexão acerca do modo pelo qual se organiza a dinâmica do trabalho escolar e de como o conhecimento é tratado nesse espaço. Evidencia-se através da disposição do conhecimento na escola que nos guiamos muito mais a partir da fragmentação e hierarquização dos saberes, e esse modo de estruturar o conhecimento nas instituições escolares fornece não somente aos estudantes, mas também aos seus profissionais, uma visão também fragmentada, a qual impede, muitas vezes, estes últimos de pensar o ensino de sua "disciplina" ou área do conhecimento de modo articulado aos demais, como se elas tivessem um fim em si mesmas apenas.

Nesse sentido, a compartimentalização dos saberes dificulta o processo de transgressão, ou seja, de ir além daquele espaço delimitado pela disciplinarização do conhecimento, ultrapassando os limites do trânsito entre as disciplinas e alcançando uma relação transversal entre as mesmas. O que se constitui como um desafio no processo de ensino e aprendizagem escolar para estudantes, professores e comunidade escolar em geral: 
"[...] puxar os fios de cada componente curricular, recuperando a unidade perdida, trançando a escola real, parece uma tarefa para além de suas responsabilidades. [...] Isso acontece na universidade, no segundo grau e escola fundamental, na maioria dos casos, no entanto. Os alunos vão aprendendo a memorizar e repetir o que os autores consagrados disseram, sem aprender com eles a criar, a descobrir, a pensar." (ALVES E GARCIA, 2001, p.85)

Nessa dinâmica, a escola corrobora para atender a demanda imposta pelo mercado, contribuindo na formação que valoriza a aprendizagem de determinadas competências e esquece-se muitas vezes de estimular o pensamento, a crítica. Na escola assim organizada, os saberes e os espaços-tempo são hierarquizados, de acordo com a atribuição de maior ou menor relevância de determinadas áreas. O que é estabelecido através de um processo de centralização, pensado mediante a defesa de um projeto neoliberal, imaginado para que se pudesse manter maior controle sobre todo o processo.

Nessa perspectiva, os professores têm um papel importante a desempenhar no rompimento com essa tradição alienante, entendidos como intelectuais que pensam seu trabalho e refletem sobre os limites e as possibilidades das práticas desenvolvidas, reconhecendo e buscando formas alternativas de não ser silenciados pela estrutura sistêmica que induz às fragmentações do pensar e do agir.

A interdisciplinaridade, na percepção de Gallo (2001), é assim um caminho possível na minimização da compartimentalização do saber, contudo, não consegue romper com a fragmentação e hierarquização presentes na escola. Para o autor, é preciso buscar um saber não disciplinar, pois "para pensar problemas híbridos, necessitamos de saberes híbridos, para além dos saberes disciplinares". (GALLO, 2001, p. 28)

É nesse panorama que se torna relevante a discussão sobre os paradigmas arbóreo e rizomático, pois nos auxiliam a repensar a organização de nossa escola e das ações implementadas por ela, se constituindo num subsídio importante na reflexão de professores comprometidos com o pensar a função social da escola para além dos ditames do mercado.

\section{INTENCIONALIDADES E CURRÍCULO: PARA ONDE VAI A AUTONOMIA DOCENTE?}

Quando pensamos em currículo na escola básica logo nos questionamos a respeito de o que devo ensinar? o que é considerado relevante dentro do contexto didático da escola básica? Essas questões não vêm sozinhas. Aliadas a saber qual conteúdo está implicado na ação de ensinar está também a relevância de indagar os motivos dessa seleção. 
Pois currículo é escolha, é seleção. Logo, " O currículo não é um corpo neutro, inocente e desinteressado de conhecimentos. [...] A seleção que constitui o currículo é o resultado de um processo que reflete os interesses particulares das classes e grupos dominantes." (SILVA, 2004, p. 46).

Diante disso, problematizamos: O que efetivamente se ensina nas escolas? Já que reconhecemos que essa seleção é permeada também por relações de poder em que estão envolvidos grupos, e que determinam aquilo que concretamente deverá ser considerado como conhecimento de maior ou de menor relevância.

Nossa atividade na escola então orienta-se pelo que é estabelecido através dos chamados "Parâmetros Curriculares Nacionais", ou simplesmente PCN. Mas é preciso que direcionemos nosso olhar ao termo "parâmetros" com a criticidade de refletir em que medida ele se constitui como parâmetro ou como de fato um currículo mínimo nacional. A esse respeito, Geraldi, 2000, p. 118, assevera:

"Em outros países, reformas semelhantes a esta instituíram o currículo mínimo nacional mesmo. Aqui, o nome ficou Parâmetros Curriculares Nacionais (PCNs) [...] Pelo jeito que é proposto não se trata de parâmetro curricular, é currículo mínimo nacional e mais, é currículo homogeneizante, porque tem uma listagem de conteúdos, objetivos dos conteúdos e propostas de atividades e processos avaliativos."

A partir disso, retornamos a questão das influências das reformas dos anos 1990 para o cenário das políticas educacionais e para a questão do controle, e do gerenciamento de instituições estatais sob a lógica ditada pelo mercado, sob a justificativa de dar mais eficiência à máquina estatal.

O Estado, redefinindo seu papel e mantendo-se como financiador e avaliador, centraliza o controle sobre as instituições, embora houvesse descentralizado a execução de serviços, repassando sua responsabilidade, como podemos perceber a partir das discussões de Adrião e Peroni (2005).

Dentro dessas intencionalidades, a avaliação institucional exerce um papel fundamental, contribuindo para que os PCNs sejam materializados como um currículo mínimo nacional. Na medida em que a avaliação requer dos sujeitos que serão avaliados certas habilidades e competências, estas por sua vez passam a ser o vetor das atividades de ensino desenvolvidas pelos professores, sendo consideradas como prioridades no processo. 
É nesse sentido que percebemos como as áreas consideradas como de maior relevância ocupam os maiores tempos-espaço no cotidiano escolar, a exemplo das áreas da matemática e da língua portuguesa, que se destacam como presença mais marcante nos testes padronizados que são elaborados para submeter as instituições de ensino a uma avaliação que irá "atestar" a qualidade dos serviços oferecidos. Cabe a ressalva, uma qualidade total. Nessa dinâmica,

No mundo da produção se estabelece um processo de competição interna e externa que, em última instância, tem na base as mesmas propostas, organizando uma intensa seleção, uma estrutura hierarquizada de decisões e um funcionamento baseado em normas rígidas, em uma sequencia que se pretende fazer crer normal e coloca todos numa louca corrida em busca da 'qualidade total', ou a nova 'gestão de desempenho'[...] Os que não atingem o nível de qualidade apresentado como padrão indispensável à competição vão sendo excluídos...do mesmo jeito que são excluídos os alunos e alunas que não atingem o padrão estabelecido como norma na escola. (GARCIA e ALVES, 2001, p.91-92)

A escola, assim organizada, torna-se uma verdadeira empresa, gerida por uma lógica que privilegia a competitividade e a produtividade, e o seu compromisso social fica submetido e subordinado às normas estabelecidas pelo mercado, contrariando a ideia de uma escola reflexiva abordada por Isabel Alarcão.

Mas esse processo não é tão perceptível aos olhos dos sujeitos frutos de um processo que fragmenta e hierarquiza, o que inibe, como dissemos anteriormente, a visão de conjunto, o que em muitos casos fica implícito ou dito de maneira bastante sutil. A autonomia docente fica comprometida, seu papel de pensar o ensino também, já que ele fica submisso ao que fora ditado previamente pelo sistema.

Geraldi contribui na reflexão sobre a divergência entre o discurso que afirma que os professores possuem autonomia no seu fazer pedagógico e para o que efetivamente são impelidos a agir:

Nesse contexto, vocês, professor e professora, grupo de professores da escola, podem fazer tudo o que quiserem em aula e na escola, só que os seus alunos serão avaliados com base no que propôs a cartilha dos PCNs, e os resultados serão do conhecimento de todos e vão repecurtir no seu salário (direito ou não a gratificações); na escola (pode ganhar ou perder verbas). Se você aguentar tudo isso, então pode ter toda a autonomia porque não é obrigatório. (GERALDI, 2000, 119) 
Ou seja, aos professores e à escola lhes é dada uma autonomia cerceada pelo controle exercido através das avaliações, pelas quais Ihes recai a maior responsabilidade pelo sucesso ou pelo fracasso dos estudantes nesses mesmos testes padronizados. Além do fato de determinados recursos serem atrelados aos índices de desempenho, sobretudo no que tange às propaladas gratificações de "proeficiência" dos professores, que mostram nitidamente o quanto a realidade educacional está subordinada aos ditames do mercado.

Na contramão desse controle, entretanto, estão alguns modos peculiares de perceber e de se contrapor a essa influência, numa espécie de contra hegemonia. A isso vale trazer a contribuição da concepção de currículo oculto de Silva, 2004, p. 78: "[...] currículo oculto é constituído por todos aqueles aspectos do ambiente escolar que, sem fazer parte do currículo oficial, explícito, contribuem, de forma implícita, para aprendizagens sociais relevantes." (SILVA, 2004, p. 78).

Inserem-se nesse âmbito, os modos de fazer pedagógico que se circunscrevem por um currículo que não se vê expresso nos documentos oficiais, mas corresponde ao que se faz e aquilo que efetivamente acontece no interior da sala de aula.

A partir dessa ideia, podemos considerar que enquanto profissional que pensa sobre sua atividade e sobre os sujeitos nela envolvidos, preocupando-se com o compromisso social desempenhado, os professores podem desenvolver ações frente ao cotidiano como forma de resistências criando e construindo novas formas de ensinar. Ferraço (2001) entende essas ações a partir de sua leitura sobre Certeau, aproximando-as do sentido de redes de astúcias, táticas, artes de fazer.

Essa ideia de conhecimento tecido em rede traz significados importantes para a realidade do cotidiano, entendidas na perspectiva de redes complexas, plurais, imprevisíveis. A concepção de currículo em redes permite pensar a escola para além do contexto imediato, percebendo que o currículo é sujeito a imprevistos e permeado por relações não-lineares.

A partir dessa concepção, portanto, é possível compreender o currículo como uma construção, que considera as relações que as pessoas estabelecem em suas redes particulares ou aquelas que instituem a partir dos grupos a que pertencem, apreendendo os sujeitos do fazer pedagógico (o professor, o aluno, a escola em si) como elementos únicos e que para tanto, devem ter suas individualidades preservadas.

A concepção de currículo em redes pode contribuir para a proposta de construção de uma escola reflexiva com uma comunidade que pensa e repensa continuamente suas 
atividades, e que encontra no cotidiano algumas "saídas" (tomando o termo emprestado de Ferraço, 2001) às prescritividades oficiais e cria através das artes do fazer pedagógico, produzindo currículo no dia-a-dia da escola.

Isso nos mostra como é relevante que a comunidade escolar se constitua em uma comunidade que reflete e questiona seu cotidiano, tornando o elemento da crítica e da reflexão em base para a produção do conhecimento. (ALARCÃO, 2011). Afinal, qual a função que efetivamente a escola deve desempenhar? A de preparação de profissionais competentes que o mercado requer, ou ela deve caminhar para a construção, acima de tudo de pessoas, que pensam, que opinam, que podem julgar ou decidir de modo consciente aquilo que lhes é apresentado?

Muito embora as transformações impostas às políticas e aos rumos da educação brasileira percorram um trajeto que prejudica a autonomia docente e sua valorização como intelectuais que refletem e redirecionam suas ações a partir do cotidiano, há "saídas" que podem e são buscadas muitas vezes no sentido de escapar desse controle. Isso porque,

[...] a escola há de ser um espaço/tempo de redes de múltiplas relações e movimentos que permitam a criação, rica e turbulenta de novos conhecimentos. [...] A riqueza de entrar na rede é que cada um pode escolher ou mesmo dar um nó, e quanto mais nós, mais surpresas. E se aprender não é se surpreender, então o que seria? Afinal esse 'diabinhos incontroláveis' que são nossos alunos são como rizomas, que aparecem, desaparecem, retornam, se encontram, nos encontram, se afastam, se escondem, fogem, brincam todo o tempo. Que o destino de quem aprende é a liberdade e não o deixar-se controlar (GARCIA e ALVES, 2001, p. 101102)

Que os nossos paradigmas, portanto, possam ser questionados, que possamos construir saberes na dinâmica e continuidade do nosso fazer e das nossas relações pedagógicas, que precisam se constituir na tessitura de redes flexíveis, mutáveis e diversas.

\section{CONSIDERAÇÕES FINAIS}

Refletir sobre currículo na educação básica nos permite considerar que primeiramente a escola é o local em que trabalhamos com "gente" na perspectiva do que menciona Paulo Freire. Nesse contexto, portanto, é preciso pensar então que se torna incoerente tratar de tal ambiente como similar a uma loja ou qualquer empreendimento 
mercadológico.

Não se pode portanto pensar em metas estritamente objetivas ou avaliações padronizadas. Trabalhamos com a subjetividade, ou subjetividades. Não lidamos com produtos prontos ou que serão "aprontados". Aliás, os seres humanos estão num constante tornar-se, buscam seu aperfeiçoamento de maneira contínua, assim como é constante seu desenvolvimento e aprendizagem.

Logo, não podemos pensar em um fazer pedagógico que esteja desconectado dessa realidade, que não se proponha a materializar a função e o compromisso social de uma instituição que para tanto, não se vincula à pretensão de atender as premissas da produtividade, da eficiência, da lógica de mercado. É preciso encontrar saídas para construir uma escola com qualidade social, que interesse e seja interessante a quem dela verdadeiramente necessita. Caminhando na perspectiva da criticidade e da construção de uma sociedade reflexiva.

\section{REFERÊNCIAS}

ADRIÃO, T.; PERONI, V. O Público e o privado em educação: interfaces entre Estado e sociedade. São Paulo: Xamã, 2005

A educação pública e sua relação com o setor privado: implicações para a democracia educacional. Revista Retratos da escola, 2009. Disponível em: http://www.ufrgs.br/faced/peroni/docs/Revista\%20Retratos\%20da\%20Escola\%20Cnte.pdf. Acesso em 15 de set. de 2013.

ALARCÃO, Isabel.Professores reflexivos em uma escola reflexiva. São Paulo: Cortez, 2011. ALVES, Nilda; GARCIA, Regina Leite (orgs.). O sentido da escola. 3.ed. Rio de Janeiro.

BRASIL. Lei de Diretrizes e Bases da Educação Nacional. Brasília, MEC, 1996. BRASIL. Parâmetros Curriculares Nacionais. INTRODUÇÂO. Brasília, SEF:MEC, 1998.

CANDAU, Vera (org). Didática, currículo e saberes escolares. Rio de Janeiro: DP\&A, 2002.

ESTEBAN, Maria Teresa. (org.). Avaliação: uma prática em busca de novos sentidos. Rio de Janeiro: DP\&A, 2000.

LIBÂNEO, José Carlos. OLIVEIRA, João Ferreira. TOSCHI, Mirza Seabra. Educação escolar: políticas, estrutura e organização. 10 ed. São Paulo: Cortez, 2012.

LIMA, Elvira Souza. Currículo e desenvolvimento humano. Brasília, MEC, SEB, 2007.

MOREIRA, Antonio Flavio Barbosa; SILVA, Tomaz Tadeu da. (orgs). Currículo, cultura e sociedade. 7a ed. São Paulo, Cortez, 2002.

MORIN, Edgar. A cabeça bem feita: repensar a reforma, reformar o pensamento.Rio de Janeiro, Bertrand Brasil, 2003.

SAVIANI, Demerval. Escola e Democracia. Campinas, SP: Autores Associados, 2009.

SILVA, Tomaz Tadeu da. Documentos de identidade: uma introdução às teorias do currículo. $2^{a}$ ed. Belo Horizonte: autêntica, 2004. 